\title{
COMMENTARY
}

\section{On Environmental Biotechnology of Bioremediation}

\author{
Ji-Dong Gu \\ Environmental Engineering, Guangdong Technion Israel Institute of Technology, 241 Daxue Road, Shantou, Guangdong 515063, China
}

\begin{abstract}
Environmental biotechnology (EB) can play a positive and an important role in detoxifying and eliminating pollutants, and cleaning up the contaminated sites of ecosystems, but the development of any EB is based largely on the scientific knowledge and results of (micro)biology and chemistry, and then application mainly by engineering and management. Biodegradation and bioremediation by definition are different in meaning and, as a result, they must be understood and treated differently. On the fundamental basis, the biochemical reactions and the biochemical degradation pathway of any targeted toxicant concerned are basic information before the degradability of the selective pollutant by a microorganism can be claimed. Bioremediation becomes feasible for implementation with the knowledge of the biochemical reactions by the biological agent coupling with the engineering and management to achieve a successful attempt at a site. Though the degradability by a microorganism can be achieved in laboratory condition, the cleaning up of the pollutant at any site needs additional information and knowledge of the physical, chemical and ecological characteristics of the site to allow any success to be achieved. The broad EB can include utilization of pure and selective microorganisms, the biochemical reactions by either pure or mixed culture, enzymes, and metabolic products of microorganisms. In addition, microorganisms may also work in the form of biofilm to carry out the function to detoxify the toxic environmental chemicals. In addition to microorganisms, plants can play an important role in phytoremediation. Overall, EB needs at least three steps to prove its effectiveness from concept testing in laboratory, establishment of the mechanisms involved, workability in complex system and ecosystems, and lastly the implementation and practice on site. A laboratory success on degradation cannot be quickly and simply treated as a claim of EB for bioremediation for application.

Keywords: Biotechnology, bioremediation, pollutant, ecosystems, plastic, genetic engineering
\end{abstract}

Correspondence to: Ji-Dong Gu, Environmental Engineering, Guangdong Technion Israel Institute of Technology, 241 Daxue Road, Shantou, Guangdong 515063, China; E-mail: jidong.gu@gtiit.edu.cn

Received: December 21, 2020; Accepted: December 21, 2020; Published Online: January 18, 2021.

Citation: Ji-Dong Gu, 2020. On Environmental Biotechnology of Bioremediation. Applied Environmental Biotechnology, 5(2): 28-33. http://doi.org/10.26789/AEB.2020.02.002

Copyright: On Environmental Biotechnology of Bioremediation. @ $2021 \mathrm{Ji}-$ Dong Gu. This is an Open Access article published by Urban Development Scientific Publishing Company. It is distributed under the terms of the Creative Commons Attribution-Noncommercial 4.0 International License, permitting all non-commercial use, distribution, and reproduction in any medium, provided the original work is properly cited and acknowledged.

Human population increase coupled with promotion of more consumption in society has put a clearly negative pressure on the natural feedback processes for purification and nutrient cycling in ecosystems, the current public awareness of the environmental contamination and pollution as well as the climate change is mainly a result of the anthropogenic or industrial activities (Ackerman, 2014; Carson, 1962). Because of the increasing consumption of natural resources, especially the non-renewable ones as a driver for today's economy in most countries, intensive manufacturing and extraction of natural resources will continue to increase its pace to meet the demands of the growing population globally. Anthropogenic synthesis and production are important sources of the persistent toxic chemicals in the ecosystems detected today. Both point and non-point sources of pollution are still ubiquitous. As a result, the trend and intensity of pollution to natural ecosystem and the living environments will not likely to be reversed any sooner even though there is apparently an increase in education level and living standard of the world population as a whole. It is evidently true that the pristine ecological niches will be diminishing quickly in number and the current natural ecosystems will be becoming contaminated with a large quantity of different types of xenobiotics produced by industrial manufacturing in an effort to improving the convenience and also the quality of human life, e.g., anthropogenic halogenated hydrocarbons (Xu et al., 2005a, b; Cheung and Gu, 2007; Han and Gu, 2010; Mitchell and $\mathrm{Gu}, 2010$; Schwarzenbach et al., 2006), a wide range of biocidal chemicals from agriculture to households, and tiny plastics invisible to our eye from packaging or products $(\mathrm{Gu}$, 2020, 2021). Today's earth system has a new entity that has been added into it through human activities and can be called anthroposphere, referring to the human-made chemicals including persistent and toxic chemicals and also polymeric materials or the plastics ( $\mathrm{Gu}, 2020)$.

The heterogeneity of the ecosystems, consisting of lithosphere, hydrosphere, atmosphere, biosphere and anthroposphere provide a unique niche for sequestration and persistence of toxic chemicals and materials (Gu, 2018b). Most of these chemicals are designed to be extremely resistant to (bio)degradation, especially in sediments or sorbed onto clays or soot to persist for an extended period of time to resulting in accumulation to initiate biological and ecological toxicity (Gu, 2003, 2019a, b, 2020, 2021). The persistent nature of xenobiotics and polymeric materials has their fundamental important and amazing property for applications because of chemical structure and the composition dominated by carbon-carbon covalent bond. As soon as a persistent 
and toxic chemical of anthropogenic production is released into the ecosystem, its physical and chemical states are in dynamic changes/modifications and the natural indigenous state is almost impossible to be captured with the most advanced analytical techniques available now. This reality, recognized and reported early (Alexander, 1999), has not been embraced fully by environmental scientists as a whole for a better understanding and knowledge of this concept for more than half a century (Dixon and Weed, 1977; Stotzky, 1986; Stumm and Morgan, 1996; Alexander, 1999; Schwarzenbach et al., 2006; $\mathrm{Gu}, 2019 \mathrm{a}, \mathrm{b})$. Because of this, a new way of analyzing and understanding the free and bioavailable fractions of the total concentration, effective concentration, of a specific toxicant is a prerequisite and the major breakthrough step to allow assessing the environmental quality and ecological safety more reliably $(\mathrm{Gu}, 2019 \mathrm{a}, \mathrm{b})$.

\section{The Effective Concentration}

An accurate measurement of a chemical's concentration in all environmental matrices is not an impossible task today with the scientific and technological advancement made, and the sophisticated instruments available, but the bioavailable fraction of the total concentration, namely effective concentration here, over time of chemical aging under any real scenario in ecosystems is actually not feasible to achieve $(\mathrm{Gu}, 2018 \mathrm{~b}$, 2019a). This fact is mainly due to the complexity and heterogeneity of the ecosystem, taking the geosphere as an example, and the dynamic nature of this fraction of the chemical in any given environmental constituents is dynamic and very different from the total concentration. Chemicals, after being released into any ecosystems, are subject to sequestration by a number of reactions, including solubilization, sorption, precipitation, complexation and transformation physically, chemically and biologically (Stotzky, 1986; Stumm and Morgan, 1996; Schwarzenbach et al., 2006), and these reactions affect the free and/or bioavailable fraction of the total concentration of a toxicant at any given time spatially. The effective concentration is rudimentary and necessary using innovative analytical chemistry or other means so that bioaccumulation and biomagnification important to the ecotoxicity and environmental risk assessment of the chemicals can be made and achieved (Schwarzenbach et al., 2006; 2020). For convenience, the total concentration of toxicants is often reported most of the time, but such values cannot be used to derive an accurate account of the ecological toxicity and risk directly because only a variable fraction of the total concentration is free and bioavailable to the target organisms in the selected environment over space and also time (Gu, 2019b).

Quantification of pollutant concentration was initially focused on the positive detection and quantification of the chemical so that the total concentration was used. With the improvement of our knowledge and also the sophistication of instrument with improved sensitivity, the physical and chemical states of the pollutants become an important parameter for an accurate assessment of the toxicity more realistically. In practice, when dealing with chemical anal- ysis of metals and metalloids in environmental samples, a chemical-based sequential extraction procedure is available to assess the specific concentration of the selective inorganic element associated with the environmental matrices, e.g., mineral oxides, organic matter, mineral structure, exchangeable or free ions in the aqueous solution (Tessier et al., 1979), but, surprisingly, a similar approach has not been developed or reported for organic pollutants (Dixon and Weed, 1977; Alexander, 1999; Gu, 2019a, b; Schwarzenbach et al., 2006). Because of the persistence and bioaccumulation nature of organic toxicants in the ecosystem, and the partition of them into the environmental matrices and the different phases of the ecosystems in different physical and chemical forms, the bioavailable concentration of each of the toxicants is a very fundamentally important numerical value to be obtained prior to any meaningful environmental quality and toxicity or risk analysis can be carried out and made. Because of this, major effort must be put into this area of fundamental protocol development so that the applied toxicology and environmental quality assessment can be conducted more meaningfully for the protection of ecosystem and human health. Due to the dynamic nature and mobility of them into atmosphere and subsurface as well as into the individual organisms of the biosphere including Homo sapiens without exception, a more realistic toxicity and risk analysis of anthropogenic pollutants to humans upon exposure is still a very important research topic with greater challenges for a long time to come in the near future (Gu, 2019a).

Both natural and anthropogenic chemicals can build up in the ecosystems because of industrial production and consumption in various sectors of the society. A wide spread of industry-based agricultural chemicals has been positively detected in different ecological niches far away from the agricultural areas, the poles where no production of such chemicals is available due to long range transportation of them by the 'grasshopper effect'. On a global basis, anthropogenic chemicals are not restricted by national or ecosystem boundary so a homogenization of them is taking place constantly for reaching a chemical equilibrium on a global scale. Different ecosystem can serve as receptor for these chemicals in some different ways, sediment and soils are far more effective sink for toxicants than aquatic ecosystem, but the mobility of chemicals is much higher in aquatic system upon a chemical spill compared with soils and sediment. Hydrophobicity of chemicals has been used to assess and predict the mobility and sequestration or accumulation of them, but the biology, especially microbiology, has a very important role to play in the transformation and mobility of these chemicals because microorganisms are capable of degrading and transforming them (Atlas, 1995; Alexander, 1999; Gu, 2019a, b; Schwarzenbach et al., 2006). In addition, microorganisms produce biosurfactant that can enhance the mobility of such hydrophobic chemicals. In a similar way, less bioavailable minerals or $\mathrm{Fe}$ and $\mathrm{Mn}$ oxides can be altered for the physical and chemical states by biological processes to result in an improved availability of toxic metals or metalloids. On the contrary, many plants can accumulate toxic metals and met- 
alloids into different parts of the plant biomass, which can be used for phytoremediation of contaminated soils (Yu and Gu, 2006, 2007a, b, 2008).

\section{Biodegradation and Bioremediation}

Organisms, large and small, over the time of evolution on earth have gained genetic traits and certain biochemical capabilities to deal with the non-favourable conditions or environments through adaptation or detoxifaction by enzymes or (bio)chemical reactions to extract energy from some of them, so that a co-existence with toxic chemicals has been developed to resist the toxicity. The mechanisms to deal with high concentration of toxicity include resistant and active efflux pump system to against otherwise a negative effect on the normal life cycle. For example, efflux pump proteins are one of the most effective ones in dealing with high concentattions of toxic chemicals in the surrounding environments, in which antibiotic resistant bacteria use this to gain a major advantage in survival and competition (Davies and Davies, 2010). Some organisms, especially microorganisms, may also evlove to take advanatge of the toxicants in their metabolic processes to extract energy by biochemical transformation and degradation of them (Atlas, 1995; Cheung and Gu, 2007; Gu, 2018b; Schwarzenbach et al., 2006). Selective examples include the reductive dechlorination of chlorinated solvents and aromatic compounds to detoxify the extreme hydrophobic and toxic chemicals by removing the chlorine by a reductive reaction using electron available from the environment, including hydrogen (Atlas, 1995). Other toxic agrochemical Atrazine can be metabolized by aerobic microorganisms as a source of carbon and energy as well as nitrogen source due to the chemical structure, but its degradation under strictly anaerobic conditons has not been proven (Atlas, 1995; Alexander, 1999; Gu, 2020; Schwarzenbach et al., 2006).

Biodegradation and bioremediation shall not be treated the same or equal in their scientific meaning or for applications. It is possible to prove a concept on the degradability of chlorinated aliphatics or aromatics by initial reductive dechlorination and then methanogenesis under sulfate-reducing or methanogenic conditions in laboratory flasks or serum bottles using mass balance and stoichiometry analysis (Atlas, 1995; Alexander, 1999; Schwarzenbach et al., 2006). Such results are fundamental and important on the mechanism level at the beginning and then useful to advance the science on the degradation processes of these chemicals, but any bioremediation of sites contaminated with such pollutants is a very different matter in practice for a cleaning up. Several key factors are critically important here to make the bridge between them. First, chemically speaking, the bioavailable fraction of these chemicals relative to the total concentration must be known. Does this fraction change over time? Are there any microorgabisms capable of degrading the pollutants in the selective environemt? Are they active metabolically? If not or too fewer, a natural response is to inoculate with the laboratory isolate to the contaminated sites or treatment reactor systems. There is not a good number of studies on tracing the inoculated microorganisms for its full expression of the metabolic capabilities in situ. Most of the time, degradation of a selective toxicant in laboratory demostration would be used for a claim for bioremediation or cleaning up the contaminated sites, which raises a big questiom because there is a large gap between biodegradation and bioremediation. Biodegradation in flask and bioreactior has major implication for possible bioremedaitiona and cleaning up, but the on site bioremediation to clean up the pollutant must be assessed with data and knowledge of the chemicals, bioavailablity, site characteristics, and the in situ bioactivity of the potential degradding microorganisms in addition to the climate conditions. Furthermore, when inoculation of a target microorganism is anticipated, a proof of the introduced one and its metabolic activity shall be conducted with labelling technique of the microorganisms and then close monitoring to establish the science. Such information is hardly presented in many papers with claim for bioremediation. Some of the successful cases on bioremediation are in boreactors (Atlas, 1995) or in field conditions where natural attenuation is an indispensable contributor to the detoxification observed. It is misleading when a claim is made after inoculating both the cultured microorganisms together with the culture medium into soil plus an amendment of a chemical at the same time, and then analyze the concentration of the pollutants to draw conclusion. Similarly, microbial culture is added into reactor system and then claim the effectiveness on pollutant removal in terms of the concentration decline is due to the inoculation boldly.

Hydrocarbons may be utilized by microorganisms during their metabolism or co-metabolism, but degradation of metals and metallioids is a myth except for a few cases and many of the papers reporting on microbial immobilization of toxic metals and metalloids has no true implication of any clean up because microorganisms assimilate and preciptate or immobilize the toxic metas and metalloids, but after death, mineralization of the cellular biomass would release the previous immobilized metals and metalloids again. Such cyclic nature of the microbial process is largely ignored to present the selective effect of them. In addition, phytoremediation is not being investigated as it should be because plants can transpire selective toxic solvents that are too toxic to microorganisms and can remove them from the soils or groundwater into the air for photo-detoxification to eliminate the toxic chemicals or by assimilation and immobilization of the plants to accumulate them in the biomass of plants as an example. For this, hydroponic systems can be used to demonstrate the success of the concept and also the mechanisms involved when dealing with phytoremediation system for removal of toxic metals and metalloids (McIntyre, 2003; Yu and Gu, 2006, 2007a, b, 2008; Kuffner et al., 2008). Practical applications must be based on solid and convincing scientific results. Science and application are separated by the reality of the characteristics of the physical world because the former is a pure conceptual assessment while the latter is solving a specific problem. Each of them has its entity and shall be treated in different ways to serve the arena of 
science and technological development today. Any further stretch of the research results for a far fetched speculation is not going to serve the technological development well. This is the pitfall facing potential technology.

\section{Environmental Biotechnology}

Environmental biotechnology (EB) can be developed based on the fundamental science, engineering, and applications to solve the environmental issues in manufacturing sites and also the ecosystems. EB has its foundation on at least two important pillars equally, biology and chemistry, and additional engineering and management, can also be involved (Figure 1). A sound BT shall be proven first with the organisms, biochemical process, and the specific chemical reactions to pave the way for the concept of the technology for any prototype trial or scale up to be tested (Liu et al., 2018). This mirrors the same situation with biodegradation or bioremediation on different scales, and both fundamental biology and chemistry are required to build a solid foundation for the mechanism involved, concept and technology to be developed. There are some oversights in published papers in which the two cornerstones of the BT have not been examined closely by vigorous critical analysis of the biology and chemistry at the same time to advance the results for a promising BT. One of the shortcomings is from the fact that no detailed chemistry is revealed from an organism and the mechanism, but it is only based on concentration differences between inoculation of the microorganism or without.

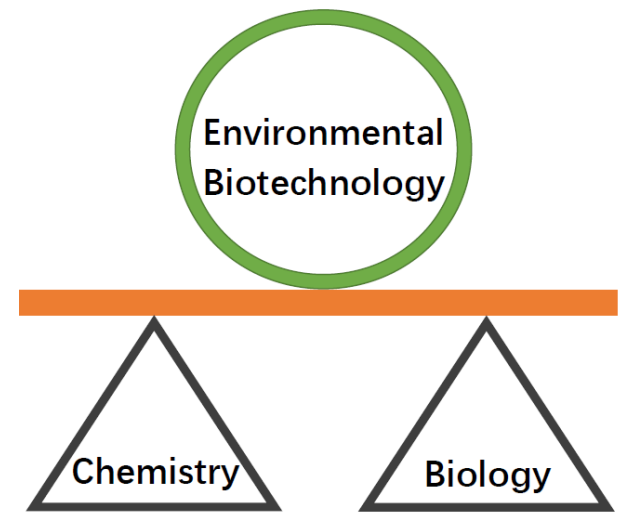

Figure 1. A schematic illustration of the foundation of environmental biotechnology as a discipline support by mainly both chemistry and biology

BT can be useful measure to mitigate environmental pollution, but it cannot be regarded as all purposes for all problems facing the development and industrialization. The anthroposphere is a real new identity of the ecosystem now $(\mathrm{Gu}, 2020)$ and there is no way that industrial footprints can be erased with the new BT today or in the future. Our society attitude of consumption and manufacturing for development and economy will increase the intensity of contamination and pollution as well as their spread into further afar into the atmosphere and deeper into the subsurface. The occurrence of plastics and micro-plastics in the environments, e.g., water, sediment, air or organisms, will continue if no drastic decision from each individual is made to decrease and stop using such products $(\mathrm{Gu}, 2021)$.

EB can be an application with specific microorganisms including bacteria, archaea, fungi, insects and plants, enzymes and biochemical capability of selective organisms, the biochemical transformation products or intermediates to serve the environmental abatement of pollutants or toxicity (Zylstraa and Kukor, 2005). The actual application and operation can be on multiple scales, from laboratory microtubes and reactors of variable sizes manageable to full-scale application on elimination of pollutants (Meng et al., 2016; Yang et al., 2020a-d), purification of wastewater (Yang et al., 2020a-c), new energy production from greenhouse gas $\mathrm{CO}_{2}$ in oil reservoirs (Ma et al., 2018, 2019; Irfan et al., 2019; Zhou et al., 2019; Bai et al., 2020; Irfan et al., 2020a, b), full-scale of the contaminated sites, or a lake, river or wetland of the coastal environment for restoration or clean up. Treatment technology based on specific biochemical process of organisms can be applied easily in manufacuring facilities to removal toxic gases or chemicals, activated sludge is a typic example for implementation of biological processes of active microorganisms to achieve removal and degradation of a range of organic and inorganic pollutants or toxicants successfully. For example, the green technology for inorganic $\mathrm{N}$ removal in full-scale wastewater treatment plants can be achieved through activate the ananaerobic ammonium oxidation bacteria (Yang et al., 2020a-d). When examining the available information closely, the overall environmental technologies can be for elimination of pollutants and toxic chemicals and conversion of residual oil in reservoirs (Chen et al., 2020; Liu et al., 2020a, b; Wang et al., 2020), enhance production of food and nutrition, protect the substainable environment from eutrophication, and extract residual conventional energy from reservoirs or produce new eneregy suplies in variable forms (Irfan et al., 2019; Irfan et al., 2020a, b; Ji et al., 2020a, b).

\section{Future Perspectives}

It is clear from the above that BT relies on the knowledge of biology and also chemistry, so equal importance shall be placed on both of them at the beginning in education, research and product development. Since both fields have been advanced at their own pace with exciting new discoveries, continuous and constant examination of new discoveries and advances made in both fields would fuel new energy and new opportunities to new BT opportunities. Biology as a whole is at genome era for the complete blue print of all life and this bring our current understanding of any organisms large or small to an unprecedented levels in human history while chemistry is at nanoscale and quantum mechanics for information of finer molecules and their properties. Dark matter in biology is being deciphered gradually and the 3-dimension structures of more and more biologically important proteins are known to not only science but also 
application in medicine and health to save life and cure disease including early diagnostics. Both biology and chemistry are also facing new questions and challenges to the future of humans on this planet and others in the universe to establish colonization with life supporting systems tested on earth.

\section{Acknowledgements}

Research in this laboratory is supported by National Natural Science Foundation of China (No. 92051103) and Guangdong Provincial Department of Education.

\section{Conflict of Interest}

Author declares that there is no conflict of interest in the information presented here.

\section{Ethical approval}

This article does not contain any studies with human participants or animals performed by the author involved.

\section{References}

Ackerman, D., 2014. The Human Age: The World Shaped by Us. W.W. Norton, New York. 352 pp.

Alexander, M., 1999. Biodegradation and Bioremediation ( $2^{\text {nd }}$ ed.). Academic Press, San Diego, California.

Atlas, R.M., 1995. Bioremediation. Chemical and Engineering News, American Chemical Society, Washington DC, Pages 3242.

Bai, Y., L. Zhou, M. Irfan, T.-T. Liang, L. Cheng, Y.-F. Liu, J.-F. Liu, S.-Z. Yang, W. Sand, J.-D. Gu, and B.-Z. Mu, 2020. Bioelectrochemical methane production from $\mathrm{CO}_{2}$ by Methanosarcina barkeri via direct and $\mathrm{H}_{2}$-mediated indirect electron transfer. Energy 210: 118445. http://doi.org/10.1016/j.energy.2020.118445

Carson, R., 1962. Silent Spring. Penguin Books, Ltd, London, UK, pp. 336.

Chen, J., L. Zhou, Y.-F. Liu, Z.W. Hou, W. Li, S.M. Mbadinga, J. Zhou, T. Yang, J.-F. Liu, S.-Z. Yang, X.L. Wu, J.-D. Gu, and B.-Z. Mu, 2020. Synthesis and mass spectra of rearrangement bio-signature metabolites of anaerobic alkane degradation via fumarate addition. Analytical Biochemistry, 600: 113746. http://doi.org/10.1016/j.ab.2020.113746

Cheung KH, Gu J-D, 2007. Mechanisms of hexavalent chromium detoxification by bacteria and bioremediation applications. International Biodeterioration \& Biodegradation, 59: 8-15. http://doi.org/10.1016/j.ibiod.2006.05.002

Davies, J., Davies, D., 2010. Origins and evolution of antibiotic resistance. Microbiology and Molecular Biology Reviews, 74: 417-433.

Dixon J.B., Weed S.B., 1977. Minerals in soil environments. Soil Science Society of America, Madison, Wisconsin, USA. 948 pp.

Gu, J.-D., 2003. Microbiological deterioration and degradation of synthetic polymeric materials: recent research advances. International Biodeterioration \& Biodegradation, 52: 69-91.
Gu, J.-D., 2016. Biodegradation testing: so many tests but very little new innovation. Applied Environmental Biotechnology, 1(1): 9295. http://doi.org/10.26789/AEB.2016.01.007

Gu, J.-D., 2018a. The endocrine-disrupting plasticizers will stay with us for a long time. Applied Environmental Biotechnology, 3(1): 61-64.

http://doi.org/10.26789/AEB.2018.01.008

Gu, J.-D., 2018b. Bioremediation of toxic metals and metalloids for cleaning up from soils and sediments. Applied Environmental Biotechnology, 3(2): 48-51.

http://doi.org/10.26789/AEB.2018.02.006

Gu, J.-D., 2019a. Microbial ecotoxicology as an emerging research subject. Applied Environmental Biotechnology, 4(1): 1-4. http://doi.org/10.26789/AEB.2019.01.001

Gu, J.-D., 2019b. On applied toxicology. Applied Environmental Biotechnology, 4(2): 1-4. http://doi.org/10.26789/AEB.2019.02.001

Gu, J.-D., 2020. Anthroposphere, a new physical dimension of the ecosystems. Applied Environmental Biotechnology, 5(1): 1-3. http://doi.org/10.26789/AEB.2020.01.001

Gu, J.-D., 2021. Biodegradability of plastics: the issues, recent advances and future perspectives. Environmental Science and Pollution Research, 28(2), 1278-1282. http://doi.org/10.1007/s11356-020-11501-9

Han X., Gu J.-D., 2010. Sorption and transformation of toxic metals by microorganisms. Pages 153-176. In: R. Mitchell and J-D Gu (eds) Environmental Microbiology ( $2^{\text {nd }}$ ed.), John Wiley, New York.

Irfan, M., Y. Bai, L. Zhou, S. Yuan, S.M. Mbadinga, S.-Z. Yang, J.-F. Yang, W. Sand, J.-D. Gu, and B.-Z. Mu, 2019. Direct microbial transformation of carbon dioxide to value-added chemicals: A comprehensive analysis and application potential. Bioresource Technology, 288: 121401. http://doi.org/10.1016/j.biotech.2019.121401

Irfan, M., L. Zhou, J.-H. Ji, J. Chen, S. Yuan, T.-T. Liang, J.-F. Liu, S.-Z. Yang, J.-D. Gu, and B.-Z. Mu, 2020a. Enhanced energy generation and altered biochemical pathways in an enrichment microbial consortium amended with natural iron minerals. Renewable Energy, 159: 585-594. http://doi.org/10.1016/j.renene.2020.05.036

Irfan, M., L. Zhou, J.-H. Ji, S. Yuan, J.-F. Liu, S.-Z. yang, J.-D. Gu, and B.-Z. Mu, 2020b. Energy recovery from $\mathrm{CO}_{2}$ for green and sustainable environment using iron minerals as electron donor. Journal of Cleaner Production, 277: 124-134. http://doi.org/10.1016/j.jclepro.2020.124134

Ji, J.-H., Y.-F. Liu, L. Zhou, M. Irfan, S.M. Mbadinga, P. Pan, J. Chen, J.-F. Liu, S.-Z. Yang, W. Sand, J.-D. Gu, and B.-Z. Mu, 2020. Methanogenic biodegradation of $\mathrm{C}_{13}$ and $\mathrm{C}_{14} n$-alkanes activated by addition to fumarate. International Biodeterioration \& Biodegradation, 153: 104972. http://doi.org/10.1016/j.ibiod.2020.104994

Ji, J.-H., L. Zhou, S.M. Mbadinga, M. Irfan, Y.-F. Liu, P. Pan, Z.-Z. Qi, J. Chen, J.-F. Liu, S.-Z. Yang, J.-D. Gu, and B.-Z. Mu, 2020. Methanogenic biodegradation of $\mathrm{C}_{9}$ to $\mathrm{C}_{12} n$-alkanes initiated by Smithella via fumarate addition mechanism. AMB Express, 10(1): 23. http://doi.org/10.1186/s13568-020-0956-5

Kuffner M., Puschenreiter M., Wieshammer G., Gorfer M., Sessitsch A., 2008. Rhizosphere bacteria affect growth and metal 
uptake of heavy metal accumulating willows. Plant Soil, 304: 35-44.

Lin, Y., A. Chen, S. Luo, X. Kuang, R. Li, J.E. Lepo, J.-D. Gu, Q. Zeng, and J. Shao, 2019. Cyanobacterial bloom mitigation by sanguinarine and its effects on aquatic microbial community structure. Environmental Pollution, 253: 497-506. http://doi.org/10.1016/j.envpol.2019.07.060

Liu, X., L. Shi, and J.-D. Gu, 2018. Microbial electrocatalysis: Redox mediators responsible for extracellular electron transfer. Biotechnology Advances, 36: 1815-1827. http://doi.org/10.1016/j.biotechadv.2018.07.001

Liu, Y.-F., J. Chen, Z.-L. Liu, L.-B. Shao, D.-D. Lin, L. Zhou, S.-Z. Yang, J.-F. Yang, J.-D. Gu, and B.-Z. Mu, 2020a. Anaerobic degradation of paraffins by thermophilic actinobacteria under methanogenic conditions. Environmental Science \& Technology, 54: 10610-10620. http://doi.org/10.1021/acs.est.0c02071

Liu, Y., J. Chen, L. Zaramela, L.-Y. Wang, S.M. Mbdinga, Z.W. Hou, X.-L. Wu, J.-D. Gu, K. Zengler, and B.-Z. Mu, 2020b. Genomic and transcriptomic evidence supports methane metabolism in Archaeglobi. mSystems, 10: 11. http://doi.org/10.1128/mSystems.00651-19

Ma, L., L. Zhou, M. Mbadinga, J.-D. Gu, and B.Z. Mu, 2018. Accelerated $\mathrm{CO}_{2}$ reduction to methane by zero valent iron in oil reservoir production water. Energy, 147: 663-671. http://doi.org/10.1016/j.energy.2018.01.087

Ma, L., L. Zhou, M.-Y. Ruan, J.-D. Gu, and B.Z. Mu, 2019. Simultaneous methanogenesis and acetogenesis from the greenhouse carbon dioxide by an enrichment culture supplemented with zero-valent iron. Renewable Energy, 132: 861-870. http://doi.org/10.1016/j.renene.2018.08.059

McIntyre T, 2003. Phytoremediation of heavy metals from soils. Advances in Biochemical Engineering/Biotechnology, 78: 97123.

Meng, H., Y.-F. Wang, H.-W. Chan, R.-N. Wu, and J.-D. Gu, 2016. Co-occurrence of nitrite-dependent anaerobic ammonium and methane oxidation processes in subtropical acidic forest soils. Applied Microbiology and Biotechnology, 100(17): 7727-7739.

Mitchell, R, J.-D. Gu, 2010. Environmental Microbiology ( $2^{\text {nd }}$ ed.), John Wiley \& Son,

Schwarzenbach, R.P., B.I. Escher, K. Fenner, T.B. Hofstetter, C.A. Jonson, U. von Gunten, B. Wehrli, 2006. The challenge of micropollutants in aquatic systems. Science, 313: 1072-1077.

Stotzky, G., 1986. Influence of soil mineral colloids on metabolic processes, growth, adhesion, and ecology of microbes and viruses. Pp. 305-428. In P.M. Huang and M. Schnitzer, eds. Interactions of Soil Minerals with natural Organics and Microbes. SSSA Special Publication No. 17. Soil Science Society of America, Inc., Madison, WI.

Stumm W, Morgan JJ, 1996. Aquatic chemistry: chemical equilibria and rates in natural waters. ( $3^{r d}$ ed.), Wiley, New York. pp. 1022.

Tessier A, Campbell PGC, Biosson M., 1979. Sequential extraction procedure for the speciation of particulate trace metals. Analytical Chemistry, 51: 844-850.
Wang, H., J. Li, Y. Zhao, C. Xu, K. Zhang, J. Li, L. Yan, J.-D. Gu, D. Wei, and W. Wang, 2020. Establishing practical strategies to run high loading corn stover anaerobic digestion: methane production performance and microbial responses. Bioresource Technology, 310: 123364.

http://doi.org/10.1016/j.biortech.2020.123364

Xu XR, Li HB, Gu J-D, 2005a. Reduction of hexavalent chromium by ascorbic acid in aqueous solutions. Chemosphere, 57:609-613

$\mathrm{Xu}$ XR, Li HB, Gu J-D, Li XY, 2005b. Kinetics of the reduction of chromium (VI) by vitamin C. Environmental Toxicology \& Chemistry, 24: 1310-1314

Yang, Y., M. Li, Z. Hu, H. Shim, J.-G. Lin, X. Li, and J.-D. Gu, 2020a. Deep insights into the active microbiota in four full-scale wastewater treatment plants showing visible anammox granules by $16 \mathrm{~S}$ rRNA gene and $16 \mathrm{~S}$ rRNA high-throughput sequencing. Journal of Cleaner Production, 276: 124176. http://doi.org/10.1016/j.jclepro.2020.124176

Yang, Y., J. Pan, Z. Zhou, J. Wu, Y. Liu, J.-G. Lin, Y. Hong, X. Li, M. Li, and J.-D. Gu, 2020b. Complex microbial nitrogen-cycling networks in three distinct anammox-inoculated wastewater treatment systems. Water Research, 168: 115142. http://doi.org/10.1016/j.waters.2019.115142

Yang, Y.-C., M. Li, H. Li, X.-Y. Li, J.-G. Lin, M. Denecke, and J.-D. Gu, 2020c. Recent Development and application of PCR primers for detection of anammox bacteria based on 16S rRNA and other genes. Science of the Total Environment, 734: 139387. http://doi.org/10.1016/j.scitotenv.2020.139387

Yang, Y., H. Daims, Y. Liu, C. Herbold, P. Pjevac, J.-G. Lin, M. Li, and J.-D. Gu, 2020d. Activity and metabolic versatility of complete ammonia oxidizers in full-scale wastewater treatment systems. mBio, 11: e03175-19.

http://doi.org/10.1128/mBio.03175-1

Yu XZ, Gu J-D, 2006. Uptake, metabolism and toxicity of methyl tert-butyl ether (MTBE) in weeping willows. Journal of Hazardous Materials, 137:1417-1423.

Yu XZ, Gu J-D, 2007a. Accumulation and distribution of trivalent chromium and effects on hybrid willow (Salix matsudana Koidz $\times$ alba L.) metabolism. Archives of Environmental Contamination \& Toxicology, 52: 503-511

Yu XZ, Gu J-D, 2007b. Metabolic responses of weeping willows to selenate and selenite. Environmental Science and Pollution Research, 14: 510-517

$\mathrm{Yu} \mathrm{XZ,} \mathrm{Gu} \mathrm{J-D,} \mathrm{2008.} \mathrm{The} \mathrm{role} \mathrm{of} \mathrm{EDTA} \mathrm{in} \mathrm{phytoextraction} \mathrm{of}$ hexavalent and trivalent chromium by two willow trees. Ecotoxicology, 17: 143-152

Zhou, Z., B. Liang, L.-Y. Wang, J.-F. Liu, B.-Z. Mu, H. Shim, and J.-D. Gu, 2019. Identify the core bacterial microbiome of hydrocarbon degradation and a shift of dominant methanogenesis pathways in oil and aqueous phases of petroleum reservoirs with different temperatures from China. Biogeosciences, 16: 42294241. http://doi.org/10.5194/bg-16-4229-2019

Zylstraa, G.J., J.J. Kukor, 2005. What is environmental biotechnology? Current Opinion in Biotechnology, 16(3): 243-245. 